\title{
Neuroblastom: Exaktere Diagnose durch Liquid Biopsy
}

\author{
St. Anna Kinderkrebsforschung leitet EU-weites Forschungskonsortium.
}

\begin{abstract}
Das Neuroblastom ist eine der häufigsten Krebserkrankungen des Säuglings- und frühen Kindesalters und für rund $15 \%$ aller pädiatrischen Krebstodesfälle verantwortlich. In den vergangenen Jahren hat sich herauskristallisiert, dass das Neuroblastom durch eine intratumorale Heterogenität gekennzeichnet ist, welche eine genetische Diagnose und daraus abgeleitete Therapien schwierig macht. Das europäische Projekt ONTHETRRAC (Overcoming Neuroblastoma Tumour HETerogeneity, Resistance and RecurrAnCe) soll neue Wege zu einer weniger belastenden Diagnostik und Prognoseeinschätzung für aggressive Neuroblastome aufzeigen. Die so gewonnenen Ergebnisse sollen eine individuellere Behandlung der Patienten ermöglichen.
\end{abstract}

\section{Forschungskonsortium}

Im Zentrum des Programms steht die "Flüssige Biopsie" (Liquid Biopsy), die durch hochsensitive Sequenzierungsverfahren nie da gewesene Einsichten

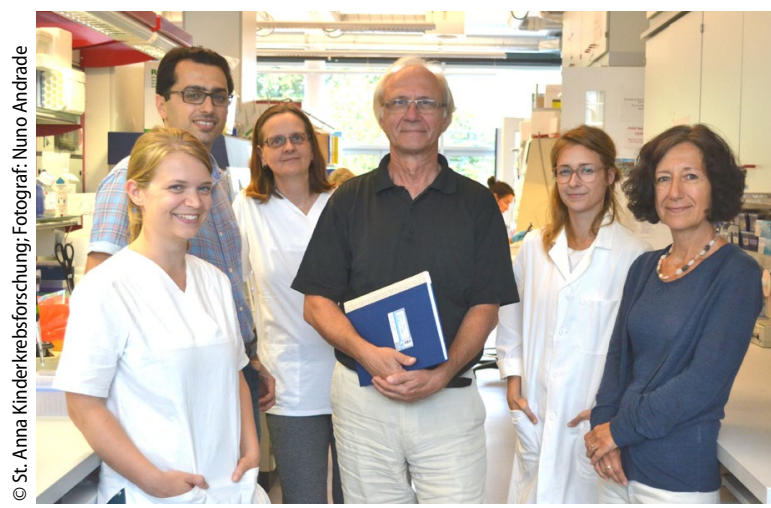

$\Delta$ Assoc. Prof. Dr. Peter Ambros, St. Anna Kinderkrebsforschung, und sein Team, v. I. n. r.: Maria Berneder, M. Reza Abbasi, Andrea Ziegler, Peter F. Ambros, Tamara Weiss, Ingeborg M. Ambros

\section{Tab. 1 Das europäische Projekt ONTHETRRAC}

\section{Projekt Koordinator:}

Peter AMBROS (Austria) St. Anna Kinderkrebsforschung/Solid Tumours

Projekt Partner:

Gudrun SCHLEIERMACHER (France) Institut Curie Département d'Oncologie Pédiatrique et INSERM U830, Paris

Angelika EGGERT (Germany) Charité - Universitätsmedizin Berlin, Department of Pediatric, Berlin

Frank WESTERMANN (Germany) Deutsches Krebsforschungszentrum DKFZ, Department of Neuroblastoma Genomics, Heidelberg

Frank SPELEMAN (Belgium) Ghent University Center for Medical Genetics, CMGG, Gent

Informationen: http://www.transcanfp7.eu/abstract/onthetrrac.html

in das Tumorgenom bieten kann. Unter der Leitung des Tumorbiologen Assoc. Prof. Dr. Peter Ambros von der St. Anna Kinderkrebsforschung haben sich vier international renommierte Institute in einem Forschungskonsortium zusammengefunden (• Tabelle 1).

Intratumorale Heterogenität auf molekularer Ebene bedeutet Uneinheitlichkeit von z. B. genetischen Mutationen innerhalb eines individuellen Tumors. Die Herausforderung besteht also darin, so viel Information wie möglich über die genetische Zusammensetzung des gesamten Tumors zu gewinnen, ohne dabei invasiv vorgehen zu müssen. Ein Ziel, das durch die Biopsie eines kleinen Tumorareals bisher nicht erreichbar war.

\section{"Liquid Biopsy"}

Das Vorliegen von freier TumorzellDNA im Blutplasma ist längst bekannt, doch bis vor Kurzem gab es noch keine Methoden, um diese geringen Mengen an zellfreier Tumor-DNA entsprechend zu untersuchen. In den letzten Jahren hat sich mit dem Einsatz von modernen Analysemethoden mehr und mehr abgezeichnet, dass diese freie Tumor-
DNA, die mittels „Flüssiger Biopsie“ aus dem Blut oder Knochenmark gewonnen werden kann, einen repräsentativen Querschnitt aller Genomveränderungen des Tumors darstellt. Der zentrale Ansatz des Projekts besteht nun darin, den Einsatz der "Flüssigen Biopsie" für das Neuroblastom zu evaluieren. Bis 2018 soll laut Ambros diese hochsensitive diagnostische Methode in der klinischen Praxis angewendet werden.

Ziele des Projekts sind verbesserte molekulare Diagnosen und auf die spezifischen Schwachstellen des jeweiligen Neuroblastoms ausgerichtete Therapien.

\section{Rückfragen \& Kontakt:} Doz. Dr. Peter F. Ambros St. Anna Kinderkrebsforschung Zimmermannplatz 10, 1090 Wien Telefon: +43 40470-4050

E-Mail: peter.ambros@ccri.at

Paediatr. Paedolog. Austria 2017 · 52:42 DOI 10.1007/s00608-017-0442-8

Online publiziert: 25. Januar 2017 (c) Springer-Verlag Wien 2017 